\title{
Dois manuais de história para professores: histórias de sua produção
}

\author{
Kazumi Munakata \\ Pontifícia Universidade Católica de São Paulo
}

\section{Resumo}

A Campanha do Livro Didático e Manuais de Ensino (Caldeme), instituída por Anísio Teixeira quando este assumiu o Instituto Nacional de Estudos Pedagógicos (Inep), em 1952, buscou produzir livros didáticos e manuais para professores, entre outros materiais didáticos. Os manuais de História do Brasil e História Geral, para professores, foram encomendados a, respectivamente, Americo Jacobina Lacombe e Carlos Delgado de Carvalho, em 1953. Este artigo acompanha a produção desses manuais, apresentando, na medida do possível, os sujeitos nela envolvidos. Os conflitos e debates são expressos em um momento particular da história educacional e se articulam ao processo de mudanças também da produção historiográfica, podendo-se identificar as relações entre as diferentes esferas de produção didática. A escolha de professores universitários para a composição de obras didáticas situa as clivagens entre produções acadêmicas e as de caráter pedagógico. Nessa perspectiva situam-se as diferenças de projetos universitários perante o problema de formação de professores. Espera-se com isso elucidar aspectos de uma política pública educacional, de âmbito federal, até agora pouco investigada. Além disso, ao acompanhar as discussões suscitadas durante a elaboração desses manuais, procura examinar as concepções sobre história e ensino de história que então se confrontaram, assim como as aproximações e separações entre a produção acadêmica e a escolar.

\section{Palavras-chave}

Livro didático - Caldeme - Ensino de História - Produção didática.

Correspondência:

Kazumi Munakata

Rua Airosa Galvão, 198

05002-070 - São Paulo - SP

e-mail: kazumi@pucsp.br 


\section{Two history manuals for teachers: histories of their production}

Kazumi Munakata

Pontifícia Universidade Católica de São Paulo

\begin{abstract}
When he took up the direction of the National Institute for Pedagogical Studies (Instituto Nacional de Estudos Pedagógicos INEP) in 1952, Anisio Teixeira started the Schoolbook and Teaching Manual Campaign (Campanha do Livro Didático e Manuais de Ensino - CALDEME) with the objective of producing schoolbooks and teaching manuals, among other didactic material. The Brazilian History and World History manuals for teachers were ordered in 1953 to Americo Jacobina Lacombe and Carlos Delgado de CarvaIho, respectively. This article follows the production of those manuals presenting, as much as possible, the characters involved in it. The conflicts and debates are expressed at a particular moment of our educational history, and relate to the process of change of the historiographical production, allowing the identification of the relations between the different spheres of the didactic production. The decision to select university teachers for the composition of those works establishes the watershed between academic productions and those of a pedagogical character. The variations between different university projects to deal with the problem of teacher education are here seen under this perspective. It is hoped that the present analysis will elucidate aspects of a public educational policy at the federal level little investigated until now. Apart from that, by following the discussions that took place during the composition of those manuals, the text seeks to examine the conceptions of History, and of its teaching, that challenged each other at that time, as well as the approximations and separations between academic and school productions.
\end{abstract}

\section{Keywords}

Schoolbooks - Caldeme - Teaching of history - Didactic production.
Contact:

Kazumi Munakata

Rua Airosa Galvão, 198

05002-070 - São Paulo - SP

e-mail: kazumi@pucsp.br 
Em 23/3/1953, Gustavo Lessa escreveu a Americo Jacobina Lacombe, confirmando um convite que lhe havia feito anteriormente:

Esta é uma confirmação oficial do pedido que vos fiz verbalmente para colaboração com o INEP [Instituto Nacional de Estudos Pedagógicos] no preparo do projeto de manuais destinados a professores secundários. Estou para isto autorizado pelo respectivo Diretor, Dr. Anísio Teixeira.

Essa colaboração se traduzirá inicialmente pela apresentação de um anteprojeto do manual para história do Brasil, com a especificação da matéria a ser tratada em cada capítulo e sub-capítulo e com a indicação do número de páginas prováveis, destinado a cada subdivisão.

(...) A título de uma retribuição simplesmente simbólica, o autor do anteprojeto receberá uma remuneração variável entre 500 e 1.000 cruzeiros.

Só mais tarde, após aprovado o anteprojeto respectivo, será combinada a remuneração pela feitura do manual.

(Carta de Gustavo Lessa Americo Jacobina Lacombe, de 23/3/1953) ${ }^{1}$

Na mesma época, convites semelhantes foram feitos a outros especialistas, de diversas instituições, para que participassem da Campanha do Livro Didático e Manuais de Ensino (Caldeme), produzindo manuais para professores de acordo com a competência de cada um: Paulo Sawaya (Zoologia); Karl Arens (Botânica); Oswaldo Frota Pessoa (Biologia Geral); Mário de Souza Lima (Português); Raymond Van der Haegen (Francês); Werner Gustag Krauledat (Química); e Carlos Delgado de Carvalho (História Geral). (Ofício de Mário P. de Brito a Anísio Teixeira, 6/1/1954)

Em artigos anteriores (Munakata, 2000 e 2002), já se apresentou a concepção que Anísio Teixeira tinha sobre livro didático e que norteava o Campanha do Livro Didático e Manuais de Ensino (Caldeme), e abordaram-se os caminhos e os descaminhos da produção do manual de Português, sob a responsabilidade de Mário de Souza Lima. 0 presente artigo pretende acompanhar, de 1953 ao final dessa década, aspectos da trajetória dos manuais referentes às histórias do Brasil e Geral, de que se encarregaram, respectivamente, Americo Jacobina Lacombe e Carlos Delgado de Carvalho. Embora o processo analisado refiram-se a livros de História, o foco não será a historiografia do período nem tampouco as modalidades de fazer-história que se constituíam então no Brasil, mas a política de produção, por instâncias governamentais, de livros didáticos e as discussões didático-pedagógicas que a acompanharam.

Todos os trabalhos acima mencionados fazem parte das investigações referentes aos projetos “A produção de livros didáticos e materiais de ensino pela Campanha do Livro Didático e Manuais de Ensino (Caldeme) e pela Campanha Nacional de Material de Ensino (CNME), do Instituto Nacional de Estudos Pedagógicos (Inep)" e "A política de livro didático no regime militar: da Campanha do Livro Didático e Manuais de Ensino (Caldeme)/Campanha Nacional de Material de Ensino (CNME) à Comissão do Livro Técnico e Didático (Colted) e à Fundação Nacional de Material Escolar (Fename)", financiados pelo Conselho Nacional de Desenvolvimento Científico e Tecnológico (CNPq), e o seu autor integra o projeto temático financiado pela Fundação de Amparo à Pesquisa do Estado de São Paulo (Fapesp), coordenado por Circe Bittencourt e intitulado "Educação e Memória: Organização de Acervos de Livros Didáticos", junto ao qual desenvolve pesquisa sobre políticas públicas e legislação referente ao livro didático no Brasil. Trata-se de um esforço para compreender esse momento impar na política pública referente aos livros didáticos no Brasil, quando o governo buscou produzir, ele próprio, os livros didáticos (Munakata, 1999). A bibliografia (Oliveira et al., 1984; Freitag et al. 1989; Xavier, 1999), de

1. Nas transcrições, a ortografia foi atualizada e a pontuação, corrigida. 
modo geral, apenas menciona essas iniciativas governamentais, sem contudo analisar-lhes 0 significado nem tampouco examinar-lhes os resultados. 0 trabalho de Saavedra (1988), sobre o Inep, talvez seja o que mais se dedique a examinar as ações da Caldeme, mas o levantamento das obras produzidas por esse órgão restringe-se à sua quantificação.

Tais investigações, de que o presente artigo representa um resultado parcial, visam preencher essa lacuna nos estudos sobre o livro didático e as políticas públicas educacionais no Brasil e, para tal, valem-se de uma documentação inédita, constituída de papéis administrativos do lnep e seus órgãos. Essa documentação havia sido levada do Rio de Janeiro quando da trasferência do Inep para a Brasília, onde permaneceu encaixotada num depósito. A professora Lucia Maria Franca Rocha, então da Universidade de Brasília, localizou-a e copiou-a em parte, até que foi impedida de prosseguir os trabalhos. Os professores Maria Rita de Almeida Toledo e Bruno Bontempi Jr., do Programa de Estudos Pós-Graduados em Educação: História, Política, Sociedade, da Pontifícia Universidade Católica de São Paulo, participaram da organização provisória desse material, constituído de ofícios, memorandos, correspondências ativa e passiva, despachos, originais dos livros e anotações sem identificação de autoria ou de data, etc. Apesar de essa documentação ser extremamente fragmentária e descontínua, por meio dela é possível elucidar aspectos de uma história que até agora se ocultava nos bastidores das decisões políticas.

Nesses bastidores, os personagens não são muito conhecidos e talvez merecessem rápida apresentação, nas notas de rodapé. Em todo caso, Anísio Teixeira (1900-1971), que está no centro de toda essa história, embora apareça pouco, não é exatamente uma figura desconhecida e sua apresentação talvez seja desnecessária. ${ }^{2}$ Basta que se diga que ele, um dos principais expoentes da chamada Escola Nova no Brasil, ao assumir a direção do lnstituto Nacional de Estudos Pedagógicos (lnep), em 1952, anunciou a necessidade de o governo produzir "guias e manuais de ensino para os professores e diretores de escolas" e também "livro didático, compreendendo o livro de texto e o livro de fontes" (Discurso de Posse do Professor Anísio Teixeira no Instituto Nacional de Estudos Pedagógicos, em 4/7/1952). ${ }^{3}$ A Campanha do Livro Didático e Manuais de Ensino (Caldeme), assim instituída, seria mais tarde transferida para o âmbito da Divisão de Estudos e Pesquisas Educacionais (Depe), do Centro Brasileiro de Pesquisas Educacionais (CBPE), cuja criação, em 1956, impôs-se na medida em que o Inep havia se transformado "num órgão mais legislador que de estudos e pequisas” (Xavier,1999, p. 84). Apesar dessas fases por que passou, a Caldeme sempre foi dirigida por intelectuais muito próximos a Anísio Teixeira, a começar por Gustavo Lessa. ${ }^{4}$

0 objetivo da Caldeme, no caso dos manuais para os professores, é assim explicitado em "Acordo celebrado entre a Campanha do Livro Didático e Manuais de Ensino (Caldeme) e o prof. Americo Jacobina Lacombe, para a elaboração de um manual de história do Brasil destinado aos professores do ensino secundário”, assinado em 16/12/1953, em sua "Cláusula 11":

A elaboração do manual será orientada pelo objetivo de promover, entre os professores secundários do país, um movimento de renovação no tocante à matéria a ser ensinada e aos métodos de ensiná-la, a fim de tornar a matéria e o método mais adequados aos

2. Sobre Anísio Teixeira, consultar, entre várias obras, o verbete a seu respeito, de autoria de Clarice Nunes, em Dicionário de educadores no Brasil (Fávero e Britto, 2002, p. 71 ss.).

3. Este texto pode ser obtido na íntegra na Biblioteca Virtual Anísio Teixeira (http://www.prossiga.br/anisioteixeira). Uma análise desse discurso encontra-se em Munakata (2000).

4. Gustavo Lessa (1888-1962) foi médico e sanitarista. Membro da Associação Brasileira de Educação (ABE), de cuja diretoria participou várias vezes a partir de 1928 (Carvalho, 1998), assumiu cargos na administração pública, quase sempre ao lado de Anísio Teixeira. Mais tarde, assumiu cargo na Fundação Getúlio Vargas, mas, em 1952, com a criação da Campanha do Livro Didático e Manuais de Ensino (Caldeme), atuou como seu diretor executivo e chefe de programa, sendo substituído por Mário Paulo de Brito em 31/12/1953, quando retornou à Fundação Getúlio Vargas. 
interesses do adolescente e ao ambiente em que vive. ${ }^{5}$

Americo Jacobina Lacombe (1909-1993), autor encarregado de promover esse "movimento de renovação” em relação ao ensino de História do Brasil, estudou Direito no Rio de Janeiro. Em 1931, foi nomeado secretário do Conselho Nacional de Educação, cargo que ocupou até 1939, quando tornou-se diretor da Casa Rui Barbosa. Ligado ao grupo católico liderado por Alceu Amoroso Lima, participou com este da fundação da Pontifícia Universidade Católica do Rio de Janeiro, onde, a partir de 1941, passou a lecionar História do Brasil. A partir de 1957, passou a dirigir a coleção "Brasiliana", da Companhia Editora Nacional, até então sob o comando de Fernando de Azevedo; em 1959-1960, exerceu o cargo de secretário de Educação e Cultura do então Distrito Federal; em 1962-1963, dirigiu a Casa do Brasil de Civilização Brasileira na École des Hautes Études de l'Amérique Latine, da Sorbonne (França); foi grande benemérito e presidente do Instituto Histórico e Geográfico Brasileiro, em substituição a Pedro Calmon; e tornouse membro da Academia Brasileira de Letras em $1974 .^{6}$

Em relação à História Geral, o autor convidado foi Carlos Delgado de Carvalho (18841980), veterano professor do Colégio Pedro $11 \mathrm{e}$ diretor da Associação Brasileira de Educação desde a primeira diretoria, sendo signatário do célebre Manifesto dos pioneiros da Educação Nova, de 1932. Estudou Direito e Ciências Políticas na França e Sociologia na London School of Economics, na Inglaterra; exerceu o cargo de vice-diretor do externato do Colégio Pedro 11; foi o primeiro diretor do Instituto de Pesquisas Educacionais (IPE), fundado em 1933 por Anísio Teixeira, quando este dirigia a Instrução Pública do Distrito Federal; e professor de Economia e Direito da Universidade do Distrito Federal, de Sociologia Educacional da Escola de Professores e de Sociologia da Escola Secundária do Instituto de Educação. Escreveu livros didáticos de Sociologia, Geografia, História e
Educação. ${ }^{7}$ Pertencia ao círculo de Teixeira e seus colaboradores, enquanto lacombe fazia parte de seus opositores católicos.

Tanto Delgado de Carvalho como Lacombe comprometeram-se a encaminhar seus respectivos planos de obra, a ser submetidos ao parecer de especialistas, antes mesmo de assinar o contrato definitivo. Não se sabe quando esses planos foram elaborados, pois não são datados, mas é possível deduzir que foram elaborados rapidamente, pois já em 9 de julho de 1953 Gustavo Lessa expedia carta a vários intelectuais solicitando-lhes um "parecer, com a possivel urgência". ${ }^{8} \mathrm{Na}$ documentação disponível, há cartas com essa solicitação endereçadas a Roberto Piragibe da Fonseca, Jayme Coelho, Helio Vianna, Eremildo Vianna, James Braga Vieira da Fonseca, todos do Rio de Janeiro, além de José Wanderley Pinho (da Bahia). Dante de Laytano (Rio Grande do Sul) foi convidado a emitir opinião somente sobre o plano de Lacombe, enquanto em relação ao plano de Carlos Delgado enviaram-se, em 5 de agosto de 1953, cartas a intelectuais da Universidade de São Paulo: Eurípedes Simões de Paula, Eduardo d'Oliveira França e Alice P. Canabrava.

Nessas cartas, todas contendo um texto padronizado, explicita-se que os manuais, a ser produzidos,

teriam por objetivo apresentar uma concepção da matéria a ser ensinada e do método de ensiná-la que permitisse satisfazer melhor as necessidades reais do adolescen-

5. Este texto é idêntico ao dos acordos firmados para a produção de outros manuais, alterando-se apenas o nome do autor e a "matéria" do livro a ser publicado.

6. Dados obtidos no site da Academia Brasileira de Letras (http:// www.academia.org.br/imortais/frame10.htm, em 29/9/2004).

7. Sobre Delgado de Carvalho, ver Campos (2002, p. 63 ss.). Informacões adicionais foram fornecidas por Karina Pereira Pinto, que desenvolve junto ao Programa de Estudos Pós-Graduados em Educação: História, Política, Sociedade, da Pontifícia Universidade Católica de São Paulo, tese de doutorado sobre o Instituto de Educação do Rio de Janeiro.

8. Num documento intitulado "Discussão dos planos dos manuais de História Geral e do Brasil, apresentados respectivamente pelos professores Carlos Delgado de Carvalho e Americo Jacobina Lacombe" (s.d.), Lessa comenta sobre a data dessa carta: "deve ter havido engano na data, e ser de 9 de agosto". 
te, e estimulasse mais a sua capacidade de reflexão do que a sua memória.

Como se trata de trabalhos sem nenhum poder coercitivo e que serão oferecidos como simples sugestões, os autores não ficam adstritos nem aos programas, nem à seriação oficial. (Carta de Gustavo Lessa a James Braga Vieira da Fonseca, em 9/7/1953)

A maioria dos pareceristas não se manifestou. Uns poucos fizeram-no oralmente, em reuniões convocadas para esse fim. $\mathrm{Na}$ primeira delas, realizada em 24 de julho de 1953, "compareceram os drs. Delgado, Lacombe e Helio Vianna”, além de, presumivelmente, Gustavo Lessa, que assina o relatório "Discussão dos planos dos manuais de história geral e do Brasil, apresentados respectivamente pelos Professores Carlos Delgado de Carvalho e Americo Jacobina Lacombe" (s.d.). Segundo esse documento, Helio Vianna apenas comentou o plano de lacombe, limitando-se a fazer apreciações superficiais:

1 - Deve ser acentuado que a bibliografia seja crítica.

2 - Na referência a "grandes autoridades", deve ser feita a restrição "no assunto".

3 - As invasões holandesas e francesas deveriam ser chamadas incursões. Dr. Lacombe de acordo.

4 - Nota que o assunto do governo geral, tratado na segunda unidade, fica restrito ao século XVl. Lacombe adverte que a unidade 7 volta ao assunto.

5 - Nesta mesma unidade propõe substituir regionais a [sic] locais. Aceito.

6 - Na unidade 8 propõe "movimento contra a metrópole" e não "movimentos nativistas". Aceito.

7 - Na mesma unidade objeta à expressão "inconfidência mineira", por denotar pejorativamente traição. Lacombe aduz argumento da tradição semântica para conservar a expressão. 8 - Acha haver demasiadas unidades para o governo de Pedro 1.
9 - Na unidade 20, acha que "a crise política de 1937" deve ser substituída pelo "Golpe de Estado de 1937”. (Discussão dos planos dos manuais de história geral e do Brasil, apresentados respectivamente pelos Professores Carlos Delgado de Carvalho e Americo Jacobina Lacombe, s.d., grifos do autor)

Em 30 de julho de 1953, foi a vez de Jayme Coelho reunir-se com os dois autores. Em relação a ambos, criticou o número de páginas previsto, considerando-o excessivo. Argumentou que se deveriam prever capítulos introdutórios "sobre metodologia e sobre obras, arquivos, bibliotecas, coleções e bibliografias a consultar". Também apresentou uma curiosa crítica, que não foi acatada: "É veementemente antagonista à divisão do assunto por unidades, achando que perturba a visão cronológica dos acontecimentos”. (Discussão dos planos dos manuais de história geral e do Brasil, apresentados respectivamente pelos Professores Carlos Delgado de Carvalho e Americo Jacobina Lacombe, s.d.) ${ }^{9}$

Os comentários específicos sobre os planos de um e de outro autor foram também bastante superficiais. Por exemplo, apontou-se que no tópico "expansão territorial”, de lacombe, "não está nitidamente incluída a 'expansão para o sul'. A conquista deve ser 'do nordeste' e não do "norte". Em relação a Delgado de Carvalho, criticou-se a falta de menção às "outras civilizações além das florescidas em torno dos quatro vales" e à "época bizantina" ou "referência às Américas muito limitada". (Discussão dos planos dos manuais de história geral e do Brasil, apresentados respectivamente pelos Professores

9. Hery (1999), em seu livro sobre o ensino de História no Liceu francês, também constata essa dificuldade de adequar a suposta continuidade histórica às unidades demarcadas pela aula. Concebido como cours (curso), o ensino de História deveria obedecer à "regra absoluta do percurso integral" (Journal officiel de la république française). Mas como apresentar esse "percurso integral" se a cada unidade de aula ele deve ser interrompido? Segundo Hery, a solução foi a introdução, no início de cada aula, da interrogation (interrogação), perguntas dirigidas a um aluno individual, a um grupo de alunos ou a classe inteira. Então o paradoxo: para assegurar a continuidade do "percurso integral", o curso torna-se descontínuo. 
Carlos Delgado de Carvalho e Americo Jacobina Lacombe, s.d.)

Um outro parecerista (Eremildo Vianna) agendou uma reunião, mas não compareceu. Outros também não responderam, à exceção de Eurípedes Simões de Paula - cujo parecer sobre o plano de Delgado de Carvalho será comentado posteriormente. Gustavo Lessa, numa carta a Lacombe, de 23 de novembro de 1953, desabafaria, dizendo que estava "cansado de esperar resposta dos professores convidados" e que, por isso, "apelei para o nosso comum amigo José Honório Rodrigues (...). Não pôde fazê-lo por escrito, mas tomei as notas inclusas sobre a convesa que tivemos" (Carta de Gustavo Lessa a Americo Jacobina Lacombe, de 23/11/1953).

Alguns comentários de José Honório Rodrigues voltam-se contra o excessivo tamanho previsto da obra ou contra a desproporção entre as partes. Há também uma discussão sobre a inconveniência de "separar os fatores econômicos dos fatos históricos a que eles precedem" ou sobre o caráter "acessório" que o "fator econômico" acaba apresentando "em relação ao político”. Além disso, Rodrigues aponta para a necessidade de se tratar, no preâmbulo de cada unidade, dos "precedentes históricos do tema". Por fim, afirma não ser "necessária a indicação de trabalhos literários, nem que seja possível a inclusão de documentos históricos fundamentais". (Notas tomadas de uma conversa com o Dr. José Honório Rodrigues, em 18 de novembro de 1953, sobre o plano do manual de história do Brasil formulado pelo Dr. Americo Jacobina Lacombe)

As anotações de Gustavo Lessa sobre a conversa com Rodrigues, extremamente telegráficas, não permitem muitas ilações. Em todo caso, Rodrigues, ao que parece, tecia seus comentários a partir de um padrão de fazer-histórico que recusa a supremacia do político e busca estabelecer relações de causalidade entre os "fatores (econômicos)" e os "fatos históricos". Rodrigues também repudiou o tópico do plano de Lacombe que propunha a "indicação de lei- turas de obras literárias, inclusive poesia e romance que despertem interesse para o tema, seguida de pequena crítica" (Plano para o manual de História do Brasil preparado pelo prof. Americo Jacobina Lacombe, s.d.). Se tais posturas de Rodrigues correspondiam a uma assimilação de padrões prevalentes na Universidade de Colúmbia, nos Estados Unidos, onde estudou em 1943-1944 graças a uma bolsa concedida pela Fundação Rockefeller, é uma questão ainda a ser avaliada. ${ }^{10}$ Em todo caso, esses temas constituiriam o eixo da réplica de Lacombe.

Para este, o comentário sobre as "leituras literárias" não passavam de

(...) velha quizília do José Honório pelo aspecto formal e literário da História. A história é uma Musa, por mais que se faça ciência. Não acredito que ninguém conheça uma época histórica sem ter lido alguma cousa de típico da literatura do tempo, ou de obras literárias que descrevam a época. (...) Estas leituras não são um sorriso da sociedade, na frase infeliz no [sic] nosso Afrânio, mas análises de uma época - não científicas, mas necessárias à boa percepção dos fenômenos sociais.

(...) Uma figura é historicamente considerada de um modo; mas a lenda, que acompanha sempre a fama, a deforma e na imaginação popular ela está fixada não como está na História, mas nas páginas de uma obra literária. É preciso que isto seja citado, e que os alunos saibam compreender que todo acontecimento histórico transcende a narrativa histórica, repercute fora da ciência histórica - no folk-lore, na literatura etc. (Carta de Americo Jacobina Lacombe a Gustavo Lessa, de $1 / 12 / 1953$, grifos do autor)

10. Os dados biográficos de José Honório Rodrigues (1913-1987) foram obtidos no site da Academia Brasileira de Letras (http:// www.academia.org.br/imortais/frame10.htm, em 29/9/2004), da qual tornou-se membro em 1969. Antes de Lacombe, Rodrigues havia sido sondado para escrever o manual de História do Brasil, mas declinou ao convite alegando "outros compromissos" (Carta de José Honório Rodrigues a Gustavo Lessa, de 25/11/1952). 
A seu favor, Lacombe mencionou, no "Plano" e, sobretudo, na sua réplica, autores que recomendassem a introdução da literatura em estudos históricos. Destaque especial era conferido às obras em inglês "compêndios americanos”, ressaltava em resposta a Rodrigues:

Tomo ao acaso, um dos excelentes que estão ao meu alcance: 0 de Lynn Barnard e A. 0. Roorbach, Epochs of World Progress, New-York, 1928. No fim de cada capítulo indicam-se leituras de Historic Novels (Lá estão os Últimos dias de Pompéia, O Yankee na corte do rei Arthur, lvanhoé, etc.) Outro, o de W. F. Gordey, History of the United States, N.Y., este de 1922. No fim de cada capítulo lá vem FICTION, e seguem-se os romances que fazem os alunos interessarem-se pelos personagens. Enfim o excelente Living in our America de James Quillen e E. Krug de 1951, além dos trabalhos literários, ainda junta filmes e discos. (Carta de Americo Jacobina Lacombe a Gustavo Lessa, de 1/12/1953, grifos do autor)

Não é difícil perceber nessa polêmica o conflito em torno do estatuto científico da história e sua relação com o discurso ficcional (ou "literário"), ou, se se preferir, a disputa entre padrões "cientificista" e "humanista"." Mas, para além dessa questão epistemológica e metodológica é possível também apreender, nas considerações de lacombe, uma preocupação propriamente didática. Nas "Justificativas" do seu "Plano", ele explicava:

A indicação de leituras literárias destina-se a despertar o interesse dos alunos para a época em estudo. Muitos alunos, que não suportam o estudo cronológico da história, devoram romances históricos com gosto(...) Parece inútil insistir em que não se pretende fazer ciência histórica através dos romances, mas criar uma atmosfera de interesse e curiosidade para o período a ser estudado. (...)
Além disso, tais indicações despertarão o gosto pela leitura, um dos grandes problemas da mocidade atual. (Plano para o manual de História do Brasil preparado pelo prof. Americo Jacobina Lacombe, s.d.)

Às demais objeções de Rodrigues, Lacombe também respondeu com comentários que relevavam aspectos didáticos:

A desproporção entre a História do Império e a História Colonial é o resultado do maior interesse que devem despertar os acontecimentos à medida que se vão aproximando os tempos presentes. Todo mundo sabe que o horror despertado pela História do Brasil vem da insistência em acontecimentos que não despertam nos alunos a menor emoção. Capitanias Hereditárias são palavras fatídicas que fazem perder a alegria a muita criança. Quando queremos exemplificar o tédio provocado pelo mau ensino de nossa história, a primeira coisa que nos ocorre é a lista dos comandantes holandeses. Quando se vai podendo apelar para uma iconografia mais abundante (...) e para fatos mais citados na conversação habitual, é muito mais fácil - e mais conveniente aprofundar-se o estudo. (Carta de Americo Jacobina Lacombe a Gustavo Lessa, de 1/ 12/1953, grifos do autor)

Por fim, Lacombe descartou facilmente as questões sobre "precedentes históricos do tema" e o caráter "acessório do fator econômico”, o que é revelador da distância que sepa-

11. Lepenies (1996) mostra a disputa travada na segunda metade do século XIX em torno da legitimidade do discurso que pode enunciar o "real", estabelecendo a partilha entre o "científico" e 0 "literário": na indefinição dessa partilha, um Buffon, hoje considerado um pioneiro das Ciências Naturais, podia proclamar "Stilo primus, doctrina ultimus [Primeiro, o estilo; por último, a doutrina]" em 1753; um século depois, um Balzac, que pretendia desenvolver "Études sociales", veria a sua obra relegada ao que doravante seria denominado "literatura". Ginzburg (1991) também ressalta a intimidade ancestral entre a historiografia e o que hoje se denomina "literatura de ficção", para enfatizar a atual diferença entre ambas: enquanto a primeira busca sua legitimidade na "realidade", a ser investigada, a outra encontra na coerência discursiva a sua razão de ser (cf. Munakata, 2003). 
rava as concepções dos contendores. Para ele, nem sempre os "antecedentes da História Brasileira estão no Brasil, nem sequer na América”, o que impossibilitaria abordá-los na unidade anterior, como pretendia Rodrigues:

Assim, as lutas na fronteira do Sul tiveram antecedentes em acontecimentos diplomáticos europeus; a vinda da Corte Portuguesa tem antecedentes nas guerras napoleônicas; o movimento constitucionalista brasileiro, na revolução liberal da Europa; a queda de Pedro 1 na sua posição perante o trono português; a invasão holandesa, na incorporação espanhola e na subseqüente política de Filipe 11; e assim por diante. (Carta de Americo Jacobina Lacombe a Gustavo Lessa, de $1 / 12 / 1953)$

Para Lacombe, o problema não se situava na esfera teórica das causalidades, mas na organização da exposição didática de um determinado conteúdo.

Do mesmo modo, são de ordem didática as considerações de lacombe sobre o predomínio do político:

a verdade é que o aspecto político da História do Império é o que está realmente estudado. (...) Dar precedência aos estudos econômicos no período é entrar no terreno das hipóteses e das polêmicas. Não é ciência feita. (Carta de Americo Jacobina Lacombe a Gustavo Lessa, de 1/12/1953, grifo do autor)

Subentende-se: o que não está feito, que ainda se presta a hipóteses e polêmicas, não pode ser matéria de ensino.

Apesar de tudo, Lacombe não deixou de proceder à revisão do seu plano, a partir da qual ele e a Caldeme firmaram um acordo em dezembro de 1953, como se viu acima. Estava previsto o prazo de um ano para a entrega dos originais, mediante o que o autor receberia a remuneração de CR\$ 150.000,00, ficando os direitos autorais sob a propriedade do lnep.
(Acordo celebrado entre a Campanha do Livro Didático e Manuais de Ensino [Caldeme] e o Prof. Americo Jacobina Lacombe, para a elaboração de um manual de história do Brasil destinado aos professores do ensino secundário). Seguiram-se sucessivas prorrogações do prazo original acrescidas de suplementação na remuneração (com pagamentos antecipados), o que, de resto, era habitual nas atividades da Caldeme (cf. Munakata, 2002). Um "um último e definitivo prazo, ao fim do qual será considerado perempto o acordo celebrado" foi marcado para 31 de março de 1957, por Mário Paulo de Brito, que sucedera a Gustavo Lessa. (Circular de Mário P. de Brito a Americo Jacobina Lacombe, de 7/11/1956). ${ }^{12}$

Finalmente, uma carta de Mário P. de Brito a Americo Lacombe, datada de "abril de 1957", acusou a "localização (sic), afinal, da primeira parte dos originais do manual de História do Brasil”. Também comunicava que esses originais haviam sido encaminhados "ao prof. Guy de Holanda, para, como especialista em História do CBPE, apresentar as sugestões (...) cabíveis". Datado de 11 de abril de 1957, o parecer de Guy de Holanda ${ }^{13}$ é, no entanto, decepcionantemente lacônico: após comentar que o texto - composto de "Preliminares", "0 descobrimento" e "Início da colonização" - era "bem documentado e com orientação metodológica muito coerente", recomenda que se atualize a bibliografia e que "sejam impressos num mesmo volume pelo menos os capítulos correspondentes ao período colonial”. Por fim, aventando a possibilidade de o livro ser desdobra-

12. Mário Paulo de Brito (1884-1974) formou-se engenheiro, tornandose professor de Química na Escola Politécnica da Universidade do Rio de Janeiro. Em 1924, participou da fundação da Associação Brasileira de Educação (ABE), integrando a sua primeira diretoria e outras sucessivas (Carvalho, 1998). Ocupou vários cargos públicos e entre 1953 e 1957, foi diretor da Caldeme (dados compilados do site da Academia Brasileira de Ciências, da qual foi presidente em 1945/47: http://www.abc.org.br/ historia/mario_brito.html, em 25/9/2004).

13. Professor de Faculdade Nacional de Filosofia, Guy de Holanda por esta época estava lançando, pelo CBPE, Um quarto de século de programas e compêndios de História para o ensino secundário brasileiro. 1931-1956. No prefácio a esta obra, de 16/7/1957, declarou que ela foi redigida entre agosto e dezembro de 1956, sendo então submetida aos comentários de várias personalidades. 
do em dois volumes, afirma ser "oportuno incluir em cada um os principais documentos históricos" (Guia de História do Brasil por Americo Jacobina Lacombe, parecer assinado por Guy de Holanda).

Mais interessantes foram os comentá-rios de Gustavo Lessa apresentados, numa carta de 3 de janeiro de 1958, a pedido de Lacombe. Ressaltando a sua condição de "leigo em assunto no qual o autor dos capítulos é reconhecida sumidade" e que não mais pertence à Caldeme "à qual me prende ainda um interesse, diria eu sentimental, pela idéia que a originou”, Lessa aponta para a disparidade entre o que havia sido acordado no início e o resultado final:

Nas conversas que precederam a carta oficial, houve ampla justificação da necessidade de conter no manual o texto para os alunos. Simples indicações gerais sobre a matéria a ser ensinada em cada capítulo não habilitariam o comum dos professores, que não têm tempo para a pesquisa de novos caminhos, a libertar-se da rotina acabrunhadora de datas e de nomes das autoridades oficiais.

(...) Parece-me, porém, que, na elaboração dos capítulos 11 e 111 (o de $n^{\circ} 1$ não entra em consideração no momento, porque trata apenas de preliminares), a orientação seguida foi bem diversa.

Vejamos o capítulo 11. O texto que vem entre o preâmbulo e os apêndices ocupa apenas três páginas, e a sua simples leitura mostra que é destinado apenas aos professores, e não aos alunos. Visa, além disto, apenas recomendar certas respostas a certos problemas litigiosos, que representam uma parte do período em questão. Constitui intencionalmente uma sugestão para investigações mais minuciosas por parte dos professores. Parece-me, entretanto, que, na falta do texto para os alunos, o dos professores deveria ser muito mais extenso, pois a maioria, convém sempre lembrar, não fará as investigações sugeridas. Tenho receio de que, diante dessa escassez, apelem para os vastos quadros genealógicos, cronológicos e sincrônicos contidos no apêndice e os propinem aos alunos.

No capítulo 11 cumpre notar também a falta básica do texto para os alunos. E não vem uma orientação sobre a escolha desse texto, pois a discussão versa sobre determinados problemas do período coberto. (Carta de Gustavo Lessa a Americo Jacobina Lacombe, de 3/1/1958, grifos do autor)

A reprimenda permite constatar a radical divergência de concepção sobre o que deveria ser um manual para professor. Para Gustavo Lessa, que tinha como pressuposto um perfil de professorado secundário mal preparado, esse manual deveria ser uma espécie de livro didático (para aluno) comentado. Por isso mesmo, no seu entender, o capítulo 1 (Preliminares), "dedicado sobretudo à descrição dos grandes arquivos existentes no Brasil e no estrangeiro", carecia de real utilidade se se levasse em conta esse professorado presumivelmente "real":

Em vista dos arquivos descritos ficarem inacessíveis à grande maioria dos professores e estudantes no país, pareceria interessante aludir às fontes de documentação existentes nas cidades do interior. (Carta de Gustavo Lessa a Americo Jacobina Lacombe, de $3 / 1 / 1958$ )

Lessa também comentou a proposta, de Lacombe, de "tirar proveito" de testemunhos contraditórios,

(...) para mostrar que a tarefa do historiador consiste, precisamente, em valer-se de fontes diversas e, às vezes, divergentes, para criticálas e elaborar com elas um texto, ou uma conclusão, constrasteada com os elementos fornecidos pela ciência historiográfica. (Preliminares, original do Capítulo 1 do manual para professor de História do Brasil, de Americo Jacobina Lacombe) 
Apesar de concordar com tal proposta, Lessa ponderou:

0 exemplo citado no capítulo 1 sobre as diversas interpretações dadas ao grito de lpiranga ficaria mais elucidativo se o autor desse, em algumas linhas, um resumo dessas interpretações. Quem sabe a escassez de obras especializadas no interior verá porque muitos professores não poderão extrair o devido proveito da sugestão feita. (Carta de Gustavo Lessa a Americo Jacobina Lacombe, de $3 / 1 / 1958)$

0 pedagógico confrontava-se com o erudito. Para Lessa, o que importava não era trazer à baila as derradeiras conquistas da pesquisa histórica, mas a utilidade que um manual teria para o professor "real", de uma escola secundária em rápida expansão e que se estendia pelos rincões do Brasil.

Série posterior de correspondências entre Lacombe e diretores do CBPE mostra que o autor continuava em atraso na entrega do restante da obra, chegando a propor a contratação de um "cooperador para, sob sua orientação e responsabilidade, partilhar de elaboração do Manual de História do Brasil" ("Informação", de Jayme Abreu, coordenador da Divisão de Estudos e Pesquisas Educacionais do CBPE, a Almir de Castro, diretor-executivo do CBPE, de 5/5/ 1959). As fontes disponíveis não permitem acompanhar a continuação dessa história.

Em todo caso, consultas às bibliotecas revelam que não há registro de obras que possam se assemelhar à descrita até aqui, a não ser uma Introdução ao estudo da História do Brasil, de Americo Jacobina Lacombe, publicada em 1974 pela Companhia Editora Nacional em co-edição com a Editora Universidade de São Paulo, na coleção "Brasiliana" (vol. 349), então dirigida pelo próprio autor. A sua comparação com os originais de "Preliminares” acima referidos revela tratarem-se da mesma obra, com trechos idênticos, mas com substanciais acréscimos. 0 quadro seguinte permite visualizar ambas as obras e suas semelhanças e diferenças:

\begin{tabular}{|l|l|}
\hline \multicolumn{1}{|c|}{ Preliminares } & \multicolumn{1}{|c|}{$\begin{array}{c}\text { Introdução ao estudo da } \\
\text { História do Brasil }\end{array}$} \\
\hline & \multicolumn{1}{|c|}{ Introdução } \\
\hline 1. Fontes históricas & 1. Fontes históricas \\
\hline & 2. Setores da História \\
\hline $\begin{array}{c}\text { 2. Disciplinas auxilliares - } \\
\text { crítica histórica }\end{array}$ & 3. Disciplinas auxiliares \\
\hline & 4. Elaboração da História do Brasil \\
\hline $\begin{array}{c}\text { 3. Centros de atividade } \\
\text { histórica no Brasil }\end{array}$ & 5. Centros de atividade histórica \\
\hline & 6. Ensino de História \\
\hline $\begin{array}{c}\text { 4. Principais historiadores } \\
\text { brasileiros }\end{array}$ & 7. Historiografia brasileira \\
\hline 5. Conclusões & 8. Conclusões \\
\hline $\begin{array}{c}\text { Fontes: Preliminares (original do capítulo I do manual } \\
\text { pra professor de História do Brasil, de Americo } \\
\text { Jacobina Lacombe) e Lacombe (1974). }\end{array}$
\end{tabular}

A "Introdução" da obra de 1974 confirma a origem da publicação:

As dificuldades da elaboração deste trabalho explicam certas falhas de que se ressente. Resulta ele, inicialmente, de um esboço feito em 1956, para um manual destinado a professores, insistentemente solicitado por Anísio Teixeira, então diretor do Instituto Nacional de Estudos Pedagógicos, que planejara, com larga visão, uma grande coleção de instrumentos de trabalho para estudiosos que não dispõem dos recursos bibliográficos dos grandes centros. (Lacombe, 1974)

0 autor não esclarece o que afinal aconteceu com o tal "manual destinado a professores". Em todo caso, assimilou o preceito de que a obra deveria atender os professores do interior, "que não dispõem de recursos bibliográficos dos grandes centros (...)”.

O livro de Delgado de Carvalho passou por caminhos semelhantes. A obra, de cerca de seiscentas páginas, previa abranger, em dezesseis unidades, desde "Os quatro vales da Antiguidade" até "A evolução das ciências, letras e artes no mundo contemporâneo". Segundo o "Plano didático", cada unidade seria constituída de "narrativa" e "notas" (formadas 
de "complementos e as explicações fornecidas aos professores"). A "narrativa” seria "precedida de uma 'Preparação da Aula”", abrangendo:

a) Os objetivos visados no conhecimento dos fatos históricos a focalizar.

b) 0 quadro geográfico dos acontecimentos e sua interpretação econômica e social.

c) A perspectiva histórica: relações de causalidade.

d) Motivação - processos e métodos de despertar interesse. Palavras-chave a discutir.

(...) Em cada Unidade, a narrativa e suas notas serão seguidas de uma documentação ou "contato com a realidade histórica":

a) Mapas, datas e cronologia - ilustrações.

b) Resumos biográficos de Personalidades da Época.

c) Leituras complementares, escolhidas em autores fidedignos.

d) Textos históricos a explicar.

e) Bibliografia sumária para professor.

Por fim, haveria "Processos de Verificação da Aprendizagem”: exercícios, testes, tópicos de dissertações (Plano para o Manual de História Geral, preparado pelo Prof. Carlos Delgado de Carvalho, s.d.).

Segundo o acordo firmado em 30 de novembro de 1953, o autor teria prazo de doze meses para concluir a redação dos originais, mas nesse caso também houve sucessivas prorrogações. Em carta de 22 de dezembro de 1955 , Delgado de Carvalho comunicava que o volume correspondente à História Antiga, já entregue, havia levado sete meses de redação, o que o fazia prever que o referente à ldade Média levasse quatro meses; à ldade Moderna, cinco; e à Contemporânea, mais cinco. Atendendo ao pedido, o quarto adendo ao acordo, firmado logo em seguida, prorrogou até 31 de dezembro de 1957 a "conclusão da parte referente à História Contemporânea”, ficando "o mesmo prazo prorrogado até 31 de dezembro de 1958, para o efeito de conclusão das demais partes da obra, ainda não entregues" (Quarto adendo ao acordo celebrado em novembro de 1953, entre a Campanha do Livro Didático e Manuais de Ensino [Caldeme] e o prof. Carlos Delgado de Carvalho, para a elaboração de um manual de história geral, destinado aos professores do ensino secundário, de 31/12/ 1955). 0 prazo para a entrega da parte referente à História Contemporânea antecedia ao das demais provavelmente porque o mesmo "Adendo" autorizava Delgado de Carvalho a "dispender com auxiliares, para a preparação da parte referente à História Contemporânea, até a quantia de CR\$ 120.000,00". 0 adendo também previa que fossem contratados auxiliares "para preparação das demais partes da obra”, no valor de até $\operatorname{Cr} \$$ 72.000,00. 0 próprio autor receberia $\mathrm{Cr} \$$ 100.000,00 por cada parte entregue.

Correspondência entre a editora Civilização Brasileira e a Caldeme mostra que o volume História Geral - Antiguidade, de Delgado Carvalho, foi efetivamente publicado, provavelmente em 1956, após quase um ano de procedimentos de edição e editoração. ${ }^{14}$ Quanto ao segundo volume, referente à História Medieval, os seus originais foram encaminhados para providências de impressão em 3 de fevereiro de 1958 (Ofício de Jayme Abreu, coordenador da Depe do CBPE, a Péricles M. de Pinho, diretor-executivo do CBPE). Desta vez a publicação da obra coube à Seção de Publicações do próprio CBPE. 0 exemplar disponível na Biblioteca Nacional assinala como data de publicação o ano de 1959. Quanto aos demais volumes (Moderna e Contemporânea), não há registros em nenhuma biblioteca consultada.

14. Uma carta da Editora Civilização Brasileira a Mário P. de Brito relata que em 11/8/1955, "atendendo a uma solictação verbal de V. Sa. e do Dr. Anísio S. Teixeira, M.D. Diretor do Instituto Nacional de Estudos Pedagógicos, apresentamos por escrito o orçamento para a produção gráfica de 5.000 exemplares do livro do Dr. Delgado de Carvalho, 'História Geral - I - Antiguidade', que esse Instituto pretende lançar em sua coleção de 'Guias e Manuais de Ensino' (Carta de Ênio Silveira, diretor da Editora Civilização Brasileira, a Mário P. de Brito, de 22/3/1956, grifos do autor). Em 20/11/ 1956, em carta ao Inep, Ênio Silveira comunica que "infelizmente já se acha desmanchada a composição do livro do Dr. Delgado de Carvalho intitulado HISTÓRIA GERAL, $1^{\circ}$ tomo, ANTIGUIDADE" - 0 que é um claro indício de que a obra já havia sido impressa. Despacho na própria carta informa que "era intenção do dr. Anísio ampliar a tiragem para dez mil exemplares". 
Para terminar essa história, merece destaque a polêmica suscitada pela obra de Delgado de Carvalho, quando ainda apresentava-se como mero "Plano" a ser avaliado. Para tal, como se disse acima, em 1953 foram convidados, além dos intelectuais que também o foram para avaliar o plano de Lacombe, três historiadores da Universidade de São Paulo: Eurípedes Simões de Paula, Eduardo d'Oliveira França e Alice P. Canabrava. Por que motivo? 0 espanto procede se se levar em conta que eles representavam a nova geração de historiadores do Brasil, que se orgulhava de ter sido formada diretamente por Braudel e que trilhava por caminhos distintos da tradição carioca, alicerçada no Instituto Histórico Geográfico Brasileiro (1HGB) e no Colégio Pedro 11. A respeito dessa diferença entre os establishments historiográficos do Rio de Janeiro e de São Paulo, comenta Maria Yedda Leite Linhares, que nas décadas de 1950-1960 ocupou a cadeira de História Moderna e Contemporânea da Faculdade Nacional de Filosofia, do Rio de Janeiro:

Nós também queríamos ser historiadores, dominar os instrumentos da pesquisa histórica, mas como fazer isso na cadeira de História Moderna e Contemporânea? Era humanamente impossivel. Isso trazia uma certa amargura, porque tínhamos contato com o pessoal de São Paulo, conhecíamos as teses paulistas. Por que São Paulo avançava na pesquisa e o Rio não? Acho que aí está a grande diferença entre Rio e São Paulo. Em primeiro lugar, a USP não teve os vícios de formação da Faculdade Nacional de Filosofia (...). A Faculdade Nacional de Filosofia surgiu como mais uma num conjunto de faculdades, perdeu aquela característica que tinha sido pensada no tempo do Anísio Teixeira, de ser um elemento de transformação da universidade brasileira, um local por onde passariam aqueles que quisessem ingressar depois numa faculdade profissionalizante, algo como um college americano.

Já a USP foi gerada num momento de pro- testo de São Paulo, que fora derrotado na revolução. Começou a funcionar já com a possibilidade de tempo integral, melhores salários para os professores. Eles receberam professores estrangeiros importantes, como Fernand Braudel e muitos outros. Aliás, Braudel foi muito responsável por imprimir um cunho antifeminista à USP. Mas o fato é que desde cedo se formaram grupos de pesquisa. E nunca foi proibido a professores de História Moderna e Contemporânea trabalhar com História do Brasil! Fernando Novais, Eduardo Oliveira França, que eram professores de Moderna e Contemporânea, fizeram suas teses em História do Brasil, pesquisaram aqui, em Portugal, na Espanha. Isso nunca foi proibido em São Paulo, mas no Rio, o establishment da Faculdade Nacional de Filosofia vetou qualquer autonomia, qualquer pesquisa verdadeiramente criadora dentro do curso de história. (...)

(...) Vivíamos sonhando aqui em pesquisar como eles. Agora, uma coisa que desenvolvemos muito mais do que eles foi o curso de formação de professores. Essa foi realmente a nossa grande contribuição. (Linhares, 1992)

Essas diferenças constituem o eixo em torno do qual se organizam os comentários de Eurípedes Simões de Paula, o único dos "paulistas" a avaliar o plano de Delgado de Carvalho, e a réplica deste. Na verdade, Simões de Paula (1910-1977), então catedrático da cadeira de História Antiga e Medieval, assinou o parecer juntamente com o seu assistente de cátedra, Pedro Moacyr de Campos. 0 texto, de dez páginas, recusa desde o início abordar o campo pedagógico:

$\mathrm{Na}$ verdade, não teremos necessidade de levar em conta, aqui, uma série de aspectos didáticos que deveriam ser considerados num manual a ser utilizado pelos estudantes. Poderemos libertar-nos da maior parte de preocupações deste tipo, no que diz 
respeito à exposição da matéria, o que nos permite tratar do assunto em nível mais elevado, contando com o preparo especializado que o professor já deverá apresentar. (Carta de Eurípedes Simões de Paula e Pedro Moacyr de Campos a Gustavo Lessa, de $8 / 10 / 1953$, p. 1)

Antes, porém, de "tratar do assunto em nível mais elevado", o parecer se permite aconselhar que se deva levar em conta que os alunos visados pelo manual a ser produzido são "sul-americanos, vivendo num país e num continente que, no conjunto da civilização do Ocidente, apresentam-se como sendo de origem colonial” (p. 2). Seria também necessário constatar que "são alunos das mais diversas ascendências, do ponto de vista da nacionalidade" (p. 2). Além disso, "a diferença que existe entre o estudante brasileiro e o europeu impedenos, ab initio, de recorrer aos manuais europeus como modelos para a organização de um manual brasileiro" (p. 2). Em outras palavras, a relação do aluno brasileiro com a disciplina História não pode ser a mesma que se verifica com os estudantes europeus. Daí, a proposta:

Procurar trazer, então, o campo da História para o mais perto possivel dos estudantes, e apresentá-lo sempre de maneira que estes o sintam como integrado na esfera do concreto, e não como uma abstração, tal esforço parece-nos indispensável para que o ensino de História possa corresponder a alguma real finalidade na formação do estudante. Quer-nos parecer que, do seu curso secundário de História, este poderá esperar, primeiramente, elementos que lhe permitam localizar-se devidamente no tempo e no espaço histórico, fornecendo-lhe as bases sobre as quais lhe será possivel sentirse perfeitamente integrado, tanto no campo mais restrito da sociedade em que exerce suas atividades, como nos âmbitos muito mais amplos de civilização ocidental e de Humanidade. Em segundo lugar, caberá à História proporcionar aos educandos também um fundo de cultura geral (...). Noções de história da Arte, da Filosofia, da Literatura, das Ciências, poderão ser ministradas, sempre dentro do campo histórico, é claro, e não isoladamente, uma vez que, aqui, o mais interessante será exatamente a apresentação destes diversos setores de maneira harmônica, conjugados entre si e também com o campo social, político e econômico em que se verificam as atividades com eles relacionados. Tratar-se-ia, assim, do que acreditamos poder chamar de "paisagem histórica” (...). Evitar-se-ia, assim, o que consideramos uma falha grave: a apresentação da matéria com predominância absoluta do seu aspecto político, entremeada de desconsoladoras notícias sobre as atividades culturais ou as características sociais e econômicas de países ou épocas. (p. 3-4.)

As considerações sobre as peculiaridades do aluno brasileiro fornecem, assim, ensejo para que os pareceristas apresentem o programa dos Annales, sintetizado na expressão "paisagem histórica".

$\mathrm{Na}$ réplica, em oito páginas manuscritas, Delgado de Carvalho dirige-se a Simões de Paula como "meu jovem colega", e acrescenta: "digo 'jovem' porque sou professor de História desde 1903!”. Sua resposta é direta:

Confesso que os aspectos didáticos, que o professor paulista preferiu afastar das discussões, me preocuparam mais do que a "narrativa" sobre a qual recaem a maior parte de suas observações.

Acredito que deve ser levado em consideração o tipo de aluno sul-americano que visa o ensino da História, lembrando, entretanto, que cabe neste setor maior responsabilidade ao Compêndio de História do Brasil (...). Estou perfeitamente de acordo em "procurar trazer o campo da História para mais perto possível dos estudantes" de "localizar no tempo e no espaço” os ensinamentos 
ministrados, e a "proporcionar também um fundo de cultura geral" aos educandos. Longe de mim, por fim, a idéia de uma "apresentação da matéria com predominância absoluta de seu aspecto político". (Carta de Carlos Delgado de Carvalho a Gustavo Lessa, de 27/10/1953)

Quando a discussão chega "ao nível mais elevado", o desentendimento entre ambos parece ser total. Simões de Paula declara peremptoriamente:

Inicialmente achamos que não cabe, de maneira alguma, ao ensino de História, a missão de dar explicações aos fatos históricos, motivo pelo qual, pelo menos dentro dos limites de um curso secundário, julgamos com a maior desconfiança o emprego da expressão "relações de causalidade". O legítimo objetivo deste ensino é, de nosso ponto de vista, o mundo histórico, agindo permanentemente sobre nós como uma força viva do homem em sociedade. (Carta de Euripedes Simões de Paula e Pedro Moacyr de Campos a Gustavo Lessa, de 8/10/1953, p. 4-5)

Certamente, se está condenando explicações mecânicas de causa e efeito e, de fato, Simões de Paula comenta páginas adiante: "Quanto às idéias com que não concordamos, achamse elas contidas principalmente no item c) da terceira parte do 'Plano Didático': 'A perspectiva histórica: relações de causalidade”” (p. 9). Delgado de Carvalho não perde a oportunidade:

Admito que nem sempre estamos em condições de dar todas as explicações, mas algumas relações de causalidade me parecem úteis. Por exemplo, o estudo do Antigo Regime, que precedeu a Revolução Francesa, explica muitas feições desta revolução... A Grande Guerra teve precedentes que a determinaram. Aliás, o próprio parecer alude, com razão, a "relações constantes entre os diversos setores das atividades humanas" e mais adi- ante define claramente, a meu ver, "o mundo histórico agindo permanentemente sobre nós como uma força viva que condiciona as linhas mestras da orientação da vida do homem em sociedade". Como "condicionar" sem influir e como influir sem estabelecer razões de causalidade? (Carta de Carlos Delgado de Carvalho a Gustavo Lessa, de 27/10/1953)

Simões de Paula também recomenda a “deseuropeização" da História, com o que Delgado de Carvalho concorda, mas entendendo por isso o que ele já faz, isto é, propor várias unidades do manual que não se referem à Europa. Além disso, Simões de Paula recomenda que o uso do "material documentário que acompanharia cada capítulo - gravuras, mapas, etc. - deveria ser escolhido em harmonia com o sistema de exposição da matéria, não se restingindo jamais ao campo político" (p. 7). Os comentários, então, tornam-se pontuais, e a polêmica que suscitam é bem reveladora. Num deles, Simões de Paula reclama da formulação de um dos tópicos do "Plano" de Delgado, que indicava: "0 quadro geográfico e sua interpretação econômica e social”. Simões de Paula indaga:

A rigor, trata-se da interpretação social do quadro geográfico, e não conseguimos compreender como, por exemplo, se pode interpretar socialmente a península Itálica ou as planícies russas. (Carta de Euripedes Simões de Paula e Pedro Moacyr de Campos a Gustavo Lessa, de 8/10/1953, p. 8)

Delgado de Carvalho, que também fora autor de livros de Geografia, não tem dificuldades em admitir um certo determinismo geográfico:

No princípio deste século, meu professor na Escola de Ciências Políticas de Paris, o saudoso Albert Sorel, costumava repetir em aula: "Ao estudar a história da lnglaterra, nunca esqueça que é uma ilha!”. Já, em 1804, em carta ao rei da Prússia: "A política dos Estados, dizia Napoleão, está na geografia”. Dois 
grandes geógrafos franceses [Jean] Brunhes [1869-1932] e [Camille] Vallaux [18701945] escreveram: "A História nos conta uma vida da humanidade sempre mais coordenada, subordinada e coletiva, recebendo a geografia a missão de nos ilustrar esta demonstração". Pois não foi a Polônia submetida a trágicas condições históricas pelo fato de se achar "nas planícies russas", varridas pelas invasões e sujeitas a condições econômicas, sociais e políticas que, devido a suas montanhas, a Suiça não conheceu? Em que consistiria a Questão do Oriente se os estreitos do Bósforo e Dardanelos não lhe condicionassem os episódios? Como teria nascido a idéia política das fronteiras naturais se não tivessem elas auxiliado a formação dos Grandes Estados Modernos? Como negar os imperativos do meio físico? (Carta de Carlos Delgado de Carvalho a Gustavo Lessa, de 27/10/1953)

Há outros itens polêmicos, alguns deles muito mesquinhos, mas um merece destaque. Em relação às "palavras-chave”, mencionadas no "Plano", Simões de Paula indaga:

Tratar-se-ia de um mero vocabulário dado previamente para a melhor compreensão do ponto? - Neste caso não seriam palavraschaves. Tratar-se-ia do emprego da filologia como ramo auxiliar da História? Concordamos em que seria muito bonito e muito útil, mas não fácil de se pôr em prática; lembremos, a título de exemplo, as digressões complicadas a que daria lugar o vocabulário do Feudalismo ou da Cavalaria Medieval nos diversos paises europeus. (Carta de Euripedes Simões de Paula e Pedro Moacyr de Campos a Gustavo Lessa, de $8 / 10 / 1953$, p. 8)

A resposta de Delgado de Carvalho chega a ser óvbia:
Mais uma vez, verifico um desacordo talvez provocado pela errônea interpretação da expressão "palavras-chaves”. Trata-se aí, não de “digressão complicada”, nem de "emprego da filologia como ramo auxiliar da História", mas apenas de um método útil, muito usado, aliás, como ponto de início de uma preleção em aula.

Por exemplo, ao tratar, em $2^{\text {a }}$ série colegial, do Período de Entre-Guerras, o mestre principia a discussão perguntando: "Quem foi o Tigre?”, pretexto para falar de Clémenceau e do Tratado de Versalhes. Segundo o interesse que pode despertar uma explicação, ele escolherá uma outra palavra-chave, como "depressão", "tcheka”, "putch”, ou "Concordata”. É um tipo simples de motivação, de fácil emprego. (Carta de Carlos Delgado de Carvalho a Gustavo Lessa, de 27/10/1953)

Noções de causalidade, relação com a Geografia, predomínio ou não da política, crítica ao eurocentrismo: a polêmica mobilizou os temas que demarcavam certas modalidades de fazer-história, que, então, podiam ser expressões dos padrões "paulista" e "carioca”. Mas, à sombra desse conflito, crescia uma outra polarização, que ultrapassaria as fronteiras estaduais para estabelecer uma forte clivagem entre os profissionais de história. De um lado, aqueles que privilegiam a pesquisa e a discussão acadêmicas e procuram "libertar-se" das preocupações com “aspectos didáticos”, preferindo "tratar do assunto em nível mais elevado", chegando ao requinte de preciosismo conceitual em relação a termos como "palavra-chave". De outro, os que mantêm certa incompreensão a respeito de novas proposições teóricas e metodológicas, pois preferem preocupar-se mais com os "aspectos didáticos". As discussões em torno dos livros de Lacombe e de Delgado de Carvalho revelam que essa polarização, que hoje se generalizou, já estava ali, latente e de difícil solução. 


\section{Referências bibliográficas}

CAMPOS, F. R. A sociologia da Educação nos cursos de formação de professores entre os anos 30 e 50 : um estudo da disciplina a partir dos manuais didáticos. 2002. Tese (Doutorado) - Programa de Estudos Pós-Graduados em Educação: História, Política, Sociedade, da Pontifícia Universidade Católica de São Paulo, São Paulo, 2002.

CARVALHO, M. M. C. de Molde nacional e fôrma cívica: higiene, moral e trabalho no projeto da Associação Brasileira de Educação (1924-1931). Bragança Paulista: IFAN/CDAPH/Edusf, 1998

FÁVERO, M. de L. de A.; BRITTO, J. de M. (Org.) Dicionário de Educadores no Brasil. 2. ed. Rio de Janeiro/ Brasília: Editora UFRJ/ MEC-Inep-Comped, 2002.

FREITAG, B. et al. 0 livro didático em questão. São Paulo: Cortez, 1989.

GINZBURG, C. Ekphrasis e citação. In: GINZBURG, C. A micro-história e outros ensaios. Lisboa: Difel, 1991, p. 215-232.

HERY, E. Um siècle de leçons d'historie: I'histoire ensegnée au lycée, 1870-1970. Rennes: Presses Universitaires de Rennes, 1999.

HOLANDA, G. de Um quarto de século de programas e compêndios de História para o ensino secundário brasileiro: 19311956. Rio de Janeiro: CBPE/Inep/MEC, 1957.

LACOMBE, A. J. Introdução ao estudo da História do Brasil. São Paulo: Cia. Editora Nacional/Edusp, 1974.

LEPENIES, W. As três culturas. São Paulo: Edusp. 1996.

LINHARES, M. Y. L. Entrevista com Maria Yedda Linhares. Estudos Históricos, Rio de Janeiro, v. 5, n. 10, p. 216-236, 1992.

MUNAKATA, K. As ações iniciais da Campanha do Livro Didático e Manuais de Ensino (Caldeme). In: ENCONTRO DE PESQUISA EM EDUCAÇÃ̃ DA REGIÃO SUDESTE, 5., 2002, Marília. Anais... Marília: s.n., 2002.

Não podemos fazer escolas sem livros: livro didático segundo Anísio Teixeira. In: SMOLKA, A. L.. B.; MENEZES, M. C. (Org.) Anísio Teixeira 1900-2000: provocações em educação. Campinas/Bragança Paulista: Autores Associados / Universidade São Francisco, 2000, p. 129-140.

Por que Descartes criticou os estudos que realizou no Colégio de la Flèche, mesmo admitindo que era "uma das mais célebres escolas da Europa?". In: TABORDA DE OLIVEIRA, M. A.; RANZI, S. M. F. (Org.) História das disciplinas escolares no Brasil: contribuições para o debate. Bragança Paulista: Universidade São Francisco, 2003, p. 39-99.

. Proposta de periodização para uma história dos livros didáticos no Brasil. In: JORNADAS DE HISTORIA DE LA EDUCACIÓN, 11., 1999, Bernal, Argentina, Comunicação... Bernal: s.n., 1999.

OLIVEIRA, J. B. A. et al. A política do livro didático. São Paulo/Campinas: Summus/ Unicamp, 1984.

SAAVEDRA, S. M. G. Passos e escompassos de uma instituição de pesquisa educacional no Brasil: a realidade do Inep. 1988. Dissertação (Mestrado)- Faculdade de Educação da Universidade de Brasília, Brasília, 1988.

XAVIER, L. N. O Brasil como laboratório: educação e ciências sociais no projeto dos Centros Brasileiros de Pesquisas Educacionais - CBPE/INEP/MEC (1950-1960). Bragança Paulista: IFAN/CDAPH/EDUSF, 1999.

Kazumi Munakata é professor do Programa de Estudos Pós-Graduados em Educação: História, Política, Sociedade, da Pontifícia Universidade Católica de São Paulo, e participa do Projeto Temático "Educação e memória: organização de acervos de livros didáticos", coordenado por Circe Bittencourt e financiado pela Fapesp. 